\title{
Densitometric HPTLC quantification of asiaticoside isolated from Centella asiatica (L.) Urb (Apiaceae) of Benin
}

\author{
Hippolyte GANSE ${ }^{1}$, Fernand GBAGUIDI ${ }^{1}$, Pierre O. AGBANI ${ }^{2}$, Roger G. JOSSE ${ }^{3}$, \\ Mansourou MOUDACHIROU ${ }^{1}$, Brice A. SINSIN ${ }^{2}$, Joëlle QUETIN-LECLERCQ ${ }^{4}$ and \\ Taofiki AMINOU ${ }^{3 *}$ \\ ${ }^{1}$ Laboratoire National de Pharmacognosie, Centre Béninois de la Recherche Scientifique et Technique \\ (CBRST), 01BP 06 Porto-Novo, Bénin. \\ ${ }^{2}$ Laboratoire d'Ecologie Appliquée. Faculté des Sciences Agronomiques (FSA), Université d'Abomey Calavi \\ (UAC), O1BP 526 Cotonou, Bénin. \\ ${ }^{3}$ Laboratoire d'Expertise et de Recherche en Chimie de l'Environnement et de l'Eau (LEERCE), Université \\ d'Abomey Calavi (UAC), O1BP 526 Cotonou, Bénin. \\ ${ }^{4}$ Laboratoire de Pharmacognosie, Unité CHAM, Département de Pharmacie, Université Catholique de \\ Louvain UCL 7230 Av. E.Mounier 72.1200 Bruxelle, Belgique. \\ *Corresponding author, E-mail: aminoutaofiki@yahoo.fr, Tél: + (229) 95400250
}

\begin{abstract}
Asiaticoside isolated from Centella asiatica has been found through in vitro test to serve as an active agent of healing on wounds. To quantify this compound in Centella asiatica cultivated in Benin, a new, simple and rapid High-Performance Thin-Layer Chromatography (HPTLC) method was developed and validated for its selectivity, its recovery, and its repeatability. Compounds have been separated on silica gel $60 \mathrm{~F}_{254}$ plates with ethyl acetate/methanol/water $(100 / 25 / 10, \mathrm{v} / \mathrm{v} / \mathrm{v})$, as mobile phase. The detection was done by densitometry scanning at $\lambda=600 \mathrm{~nm}$ and the calibration plots showed that the graphical response was linear and dependent on the quantity in the range of 2.50-12.50 $\mu \mathrm{g}$, with good values of $\mathrm{R}^{2}=0.998$. This method is repeatable and precise with relative standard deviations between 1.42 and 5.92\% for the intra-day tests and between 1.27 and $6.57 \%$ for the inter-day tests for the quantities belonging to an interval of 2.50 and $12.50 \mu \mathrm{g}$. The limits of detection and quantification were 0.317 and $1.05 \mu \mathrm{g}$ respectively. The quantity of asiaticoside found was $0.24 \%$ in the alcoholic extract.

(C) 2010 International Formulae Group. All rights reserved.
\end{abstract}

Keywords: HPTLC, Centella asiatica, Asiaticoside, Wounds.

\section{INTRODUCTION}

Centella asiatica (Apiaceae), a plant from India, is cultivated and often used in traditional medicine in Benin Republic to treat several diseases such as ulcers, leprosy, tuberculosis, infected wounds (De Souza, 2005). The ointments containing alcoholic extract of Centella asiatica (madecassol) are active for the healing of wounds. The active principles in this plant are saponosides among which the most important is the asiaticoside with healing properties (Posset, 2006). The healing properties of the plant on wounds and 
ulcers are due to the increase of the collagen synthesis by the fibroblasts (Maquart and Bellon, 1986; Maquart and Bellon, 1990). A recent study carried out on guinea-pigs with skin incisions and which have received injection of streptozotocine and then treated by a solution of asiaticoside gave the results which confirm the increase of collagen (Shulka and Rasik, 1999). For the ulcers of the leg, many publications pointed out the effectiveness of the asiaticoside given though 10mg tablets by oral route (Huriez, 1971). Asiaticoside, the major compound (84\%) found in Centella water extract, is one of the compounds found in Centella asiatica leaves that are suggested to be responsible for its pharmacological potential. Phospholipase $\mathrm{A}_{2}$ $\left(\mathrm{PLA}_{2}\right)$ is a group of enzymes that has abnormal activity on the central nervous system in some neuropsychiatric diseases (Barbosa et al., 2008; Veerendra et al., 2002). The putative anxiolytic activity of asiaticoside was examined in male mice by using a number of experimental paradigms of anxiety, with diazepam as a positive anxiolytic control. The asiaticoside present in Centella asiatica extract was identified and quantified by HPLC and TLC analysis (Rafamantanana et al., 2009; Zhang et al., 2008; Bonfill et al., 2006). The structure of the asiaticoside was established by Polonsky et al. (1959) and is similar to the one as shown on the Figure 1.

The purpose of this study is to verify the presence of asiaticoside in alcoholic extracts of Centella asiatica cultivated in Benin, and to establish an HPTLCdensitometric detection method for the quantification of asiaticoside in the plant.

\section{MATERIALS AND METHODS}

We have developed a simple, rapid, and cost-effective HPTLC method for the determination of asiaticoside in Centella asiatica cultivated in Benin. The criteria used for the validation of the quantitative analytical procedures are those of the SFSTP Commission (Hubert, 2000).
Chemicals and reagents, plant material, and preparation of extracts

All chemicals and solvents used were of analytical grade. The aerial parts of the plant have been collected in the area of Djregbe (near Porto-Novo, the capital of Benin Republic) and have been identified and confirmed by the National Herbarium of the University of Abomey-Calavi in the Republic of Benin where a voucher specimen (no: AA 6346/HNB) was deposited. The plant was first dried at room temperature for five days during which it was turned over every day (European Pharmacopeia, 2004). A method of extraction by ultrasound has been used as follows: 100 $\mathrm{mg}$ of powder are mixed with $10 \mathrm{ml}$ of methanol during $30 \mathrm{~min}$. The filtrate is obtained throughout filters $0.45 \mu \mathrm{m}$ diameter pores.

\section{HPTLC analysis}

HPTLC system is composed of an automatic deposer, a scanner 3 and a computer using the software winCATS 1.2.6. The chromatographic trials have been carried out on plates HPTLC (Silicagel $60 \mathrm{~F}_{254}, 10 \mathrm{~cm}$ x $20 \mathrm{~cm}$ ).

\section{Calibration curve}

A standard solution of asiaticoside with $1 \mathrm{mg} / \mathrm{ml}$ is prepared in methanol and volumes $2.5 ; 5 ; 7.5 ; 10$ and $12.5 \mu 1$ are successively placed on plates HPTLC (stationary phase) which correspond to: $2.50,5.00,7.500,10.00$ and $12.50 \mu \mathrm{g}$ of asiaticoside. These deposits are done on bands of $6 \mathrm{~mm}$ with an interval of $8 \mathrm{~mm}$ between them. The first and the last bands are at a distance of $1 \mathrm{~cm}$ from each edge. This plate was then dried at room temperature for $10 \mathrm{~min}$ and then was developed on $80 \mathrm{~mm}$ in a mobile phase previously saturated during $15 \mathrm{~min}$ and composed of ethyl acetate/methanol/water $(100 / 25 / 10, v / v / v)$ contained in a tank of a thin layer chromatograph (TLC) at a temperature of $15{ }^{\circ} \mathrm{C}$. The plate, revealed with sulphuric anisaldehyde, was dried at $100{ }^{\circ} \mathrm{C}$ during 10 min and red by Scanner 3 at $600 \mathrm{~nm}$; data 
were collected and treated by the WinCats1.2.6 Software.

Repeatability: Intraday and Inter-days precision have been determined by analyzing five standard quantities between 2.50 and $12.50 \mu \mathrm{g}$, several times $(\mathrm{n}=5)$ the same day and everyday successively $(\mathrm{n}=5)$.

Recovery: The output of extraction was given starting from powder $500 \mathrm{mg}$ with pure addition of $2 \mathrm{mg}$ of asiaticoside. Recovery $(\%)=(\mathrm{A}-\mathrm{B}) / \mathrm{C} \times 100 . \mathrm{A}$ is the quantity of asiaticoside extracted from the plant mixture powder with asiaticoside addition. B stands for the quantity of asiaticoside in the powder of the plant without asiaticoside addition. $\mathrm{C}$ represents the added quantity of pure asiaticoside.

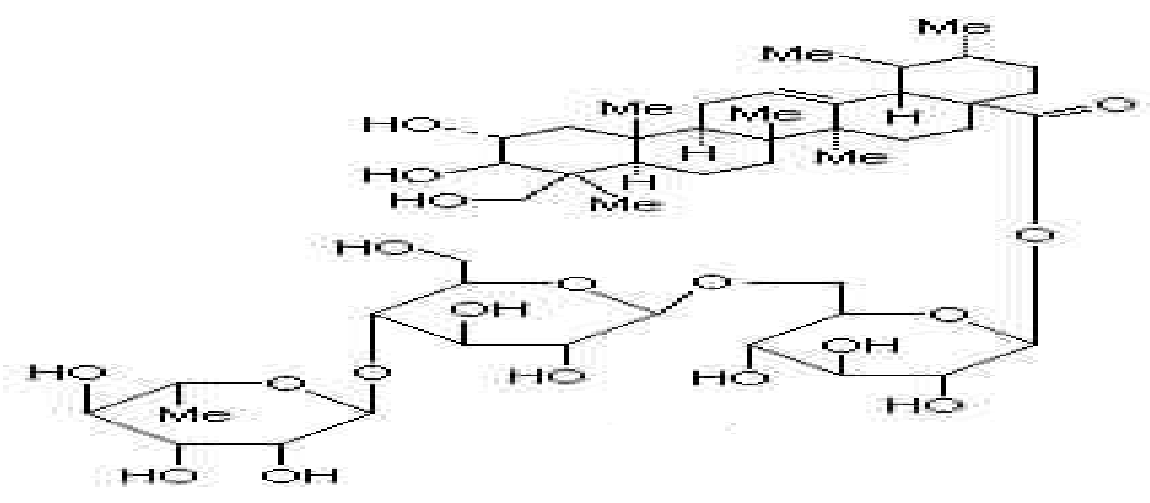

Figure 1: The structure of asiaticoside.

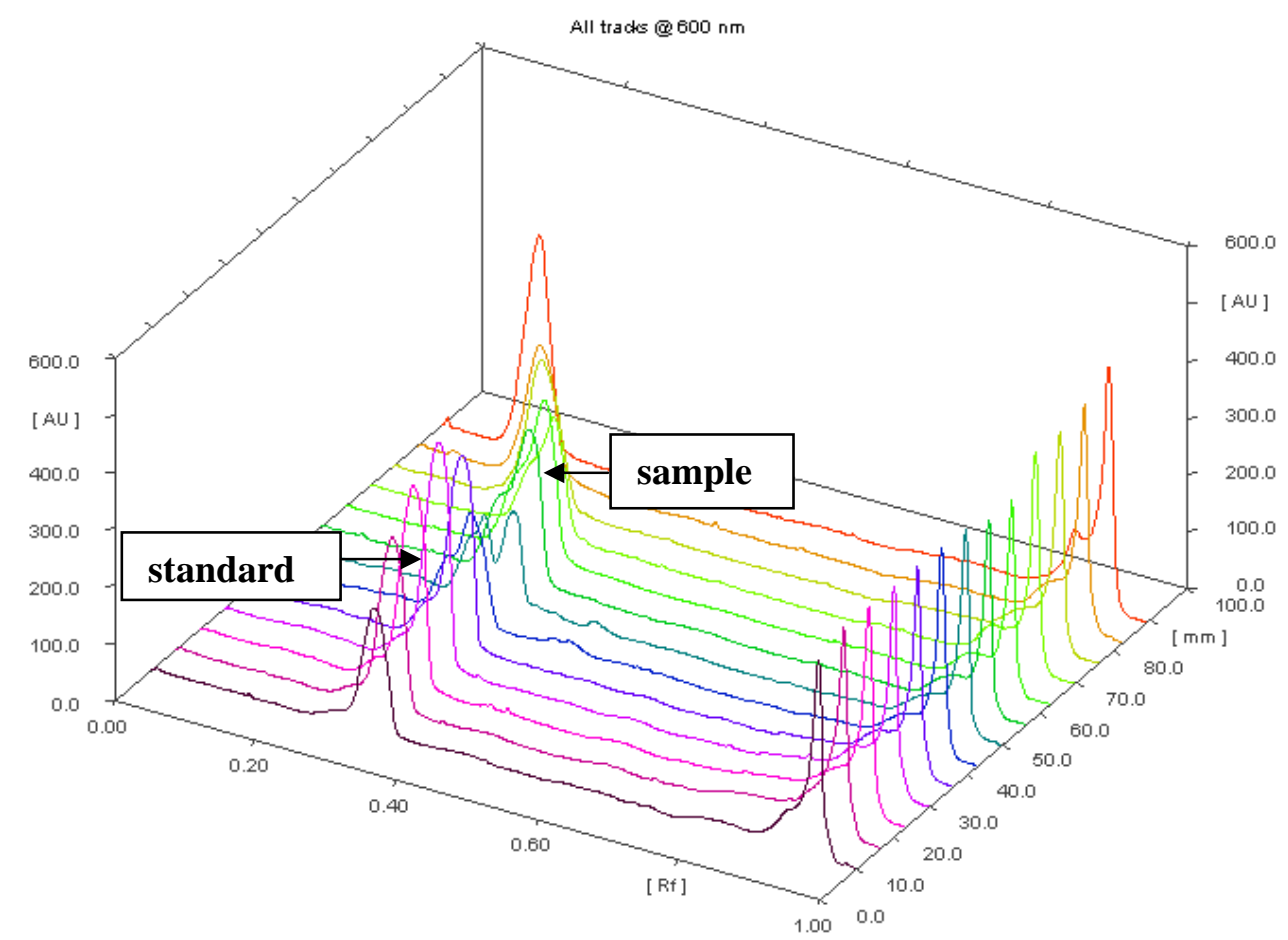

Figure 2: HPTLC all tracts at $600 \mathrm{~nm}$ (standard and sample) showing the presence of asiaticoside in alcoholic extracts of Centella asiatica leave. 

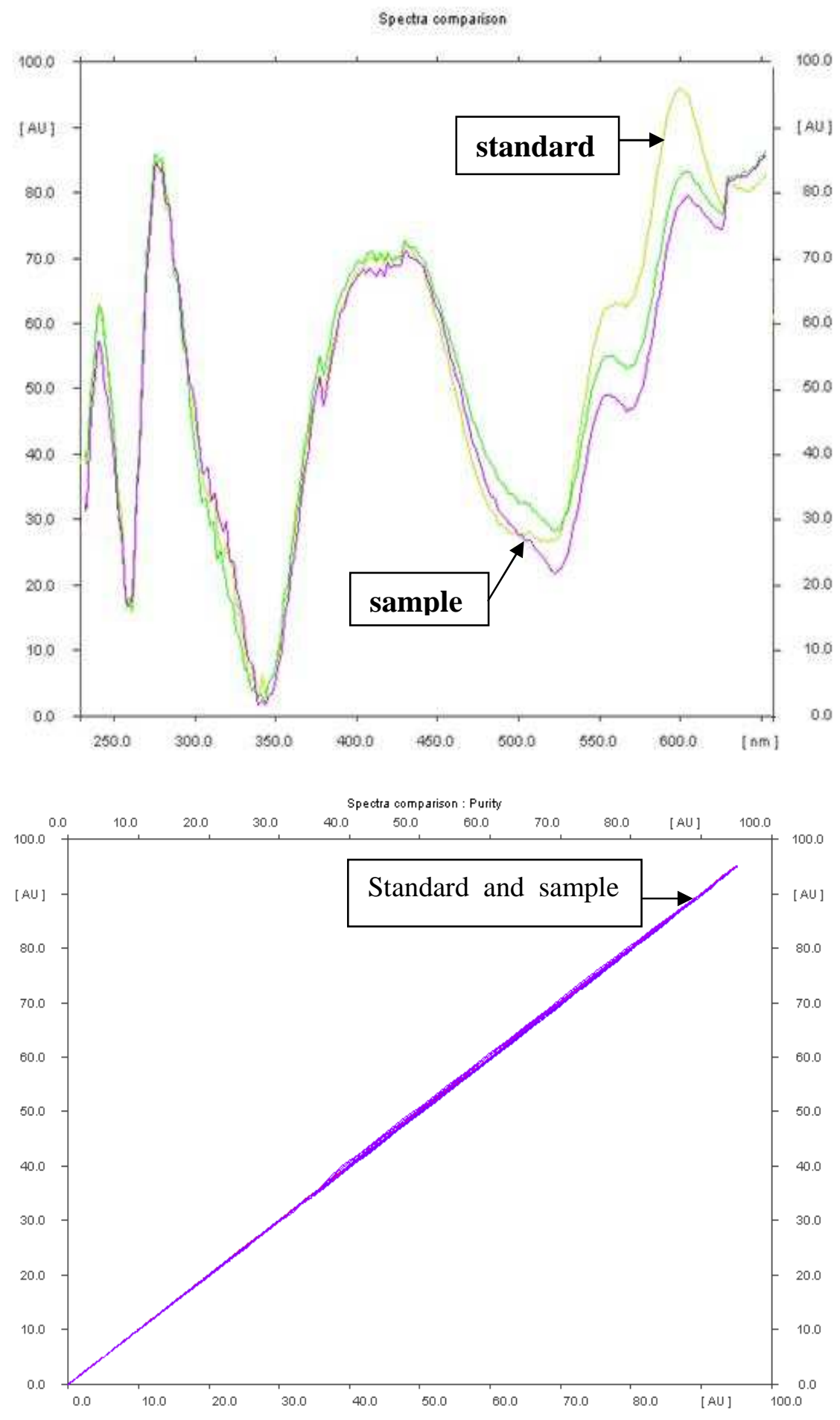

Figure 3: HPTLC Spectra comparison (standard and sample) showing the purity of asiaticoside in alcoholic extracts Centella asiatica leaves. 

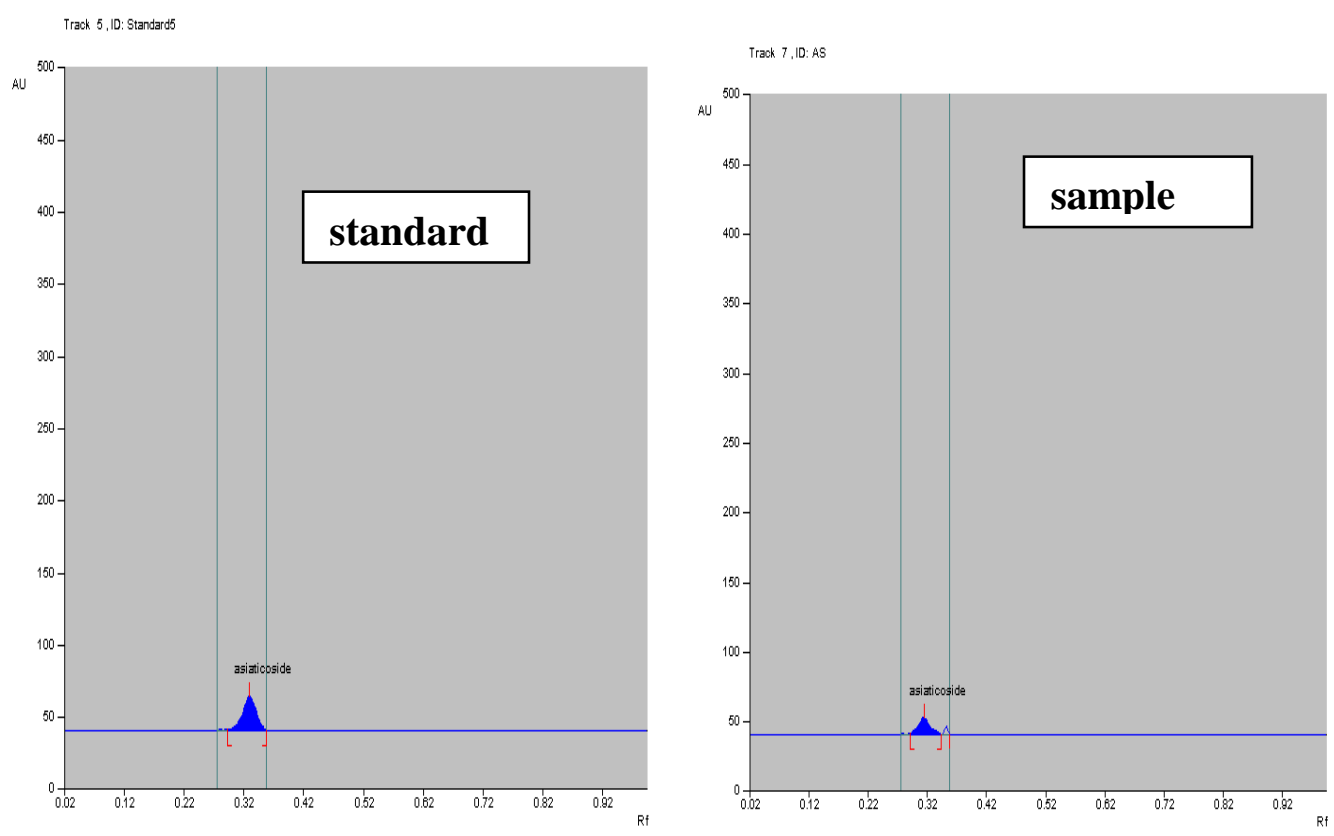

Figure 4: Typical HPTLC chromatogram obtained from Centella asiatica alcoholic extract.

Table 1: Limits of detection (LOD) and quantification (LOQ).

\begin{tabular}{lcc}
\hline Standard quantity $(\boldsymbol{\mu g})$ & LOD and LOQ \\
\cline { 2 - 3 } & & \\
\cline { 2 - 3 } $\mathbf{2 . 5}$ to12.5 & LOD $(\mathrm{ng})$ & LOQ $(\mathrm{ng})$ \\
& 317 & 1056 \\
\hline
\end{tabular}

Table 2: Inter- and Intra-day precision of the HPTLC method for quantification of asiaticoside in plant material.

\begin{tabular}{lcc}
\hline Standard quantity $(\mathbf{n g})$ & \multicolumn{2}{c}{ RSD (\%) } \\
\cline { 2 - 3 } & Intra-day $(\mathbf{n}=\mathbf{5})$ & Inter-day $(\mathbf{n}=\mathbf{5})$ \\
\hline 2500 & 3.53 & 3.94 \\
5000 & 5.92 & 6.14 \\
7500 & 1.42 & 6.57 \\
10000 & 2.35 & 4.46 \\
12500 & 3.94 & 1.27 \\
\hline
\end{tabular}




\section{RESULTS AND DISCUSSION}

An HPTLC method was used to quantify asiaticoside in the plant. The presence of asiaticoside in the alcoholic extract of Centella asiatica collected in Benin, after purification, is shown in Figures 2 and 3. The presence of asiaticoside was verified by comparison of $\mathrm{R}_{\mathrm{F}}(0.32 \pm 0.04)$ and by comparison of the UV spectra wavelengths from 200 to $700 \mathrm{~nm}$ obtained from the sample and the standard. A typical chromatogram obtained from the total alcoholic extract is shown in Figure 4.

The limits of quantification $(L O Q)$ and detection $(L O D)$ were calculated by using the following equation $L O D=3 \quad x \quad N / B$ and $L O Q=10 \times N / B$ (Hubert, 2006) where $\mathrm{N}$ is the standard deviation of the peak area of the standard, taken as a measure of noise, and $B$ representing the slope of the corresponding calibration plot. The limit of quantification was found to be $1056 \mathrm{ng}$ on the plate and the limit of detection $317 \mathrm{ng}$ on the plate. There was a linear relationship between peak area and quantity in the range of 2500 and 12500 ng on the plate for the standard. Analysis of asiaticoside standard during five different days yielded the mean calibration plot according to the equation $\mathrm{y}=0.200 \mathrm{x}+30.96$ with a correlation coefficient $\mathrm{R}^{2}=0.998$.

Inter-day $(\mathrm{n}=5)$ and Intra-day $(\mathrm{n}=5)$ variation for determination of asiaticoside were less than $10 \%$ for all the quantities analyzed (Table 2). The recovery of the method was $96 \pm 3 \%$. The quantity of asiaticoside in $100 \mathrm{mg}$ of powder of Centella asiatica was calculated as $240 \pm 10 \mu \mathrm{g}$.

\section{Conclusion}

Our study confirmed the presence of asiaticoside in Centella asiatica samples in Benin. We have developed a new HPTLC method for the quantification of asiaticoside and validated it for selectivity, recovery, and repeatability. The Relative Standard Deviation (RSD) intra-day or repeatability and interdays or intermediate precision are lower than $10 \%$ for all series of asiaticoside samples quantified by the method. We have also determined LOD and LOQ. This validated method enabled us to determine the quantity of asiaticoside to be $0.24 \%$ in its alcoholic extract.

\section{REFERENCES}

Barbosa N, Pittella F, Gattaz W. 2008. Centella asiatica water extract inhibits $\mathrm{iPLA}_{2}$ and $\mathrm{CPLA}_{2}$ activities in rat cerebellum. Phytomedicine, 15(10): 896900.

Bonfill M, Mangas S, Cusidó RM, Osuna L, Piñol MT, Palazón J. 2006. Identification of triterpenoid compounds of Centella asiatica by thin-layer chromatography and mass spectrometry. Biomedical Chromatography, 20(2): 151-153.

Chen SW, Wang W, Jing Li W, Wang R., Li YL, Huang X, Liang YN. 2006 Anxiolytic-like effect of asiaticoside in mice. Pharmacology, Biochemistry and Behavior, 85(2): 339-344.

De Souza S. 2005. Guide pratique de Phytothérapie, p.41.

European Pharmacopeia. 2004. European Council, Strasbourg.

Hubert P. 2000. Commission SFSTP (Société Française des Sciences et Techniques Pharmaceutiques): Validation des Procédures Analytiques Quantitatives: Harmonisation des Démarches, Version 4.3.

Hubert P. 2006. Validation des Méthodes Analytiques. Université de Liège; 45-46.

Huriez C. 1971. Action de l'extrait titré de Centella asiatica dans la cicatrisation des ulcères de la jambe (10 mg. Comprimés). A propos de 50 cas. Lille Méd., 17(3): 574-579.

Maquart F, Bellon G. 1986. Titrated Extract from Centella asiatica Stimulates Collagen Biosynthesis in Human Vein Wall Fibroblastic Cell Cultures. J. Libbey \& Co Ltd; 843-845.

Maquart F, Bellon G. 1990. Stimulation of collagen synthesis in fibroblast cultures by a triterpene extracted from Centella 
asiatica. Connective Tissue Research, 24: 107-120.

Neuwinger HD. 2000. African Traditional Medicine. A Dictionary of Plant Use and Applications. Medpharm Scientific Publishers: Stuttgart ; 104.

Posset J-L. 2006. Plantes médicinales d'Afrique: Comment les Reconnaitre et les Utiliser? Edisud; 269-270.

Rafamantanana MH, Rozet E, Raoelison G E, Cheuk K, Ratsimamanga SU, Hubert Ph, Quetin - Leclercq J. 2009. An improved HPLC-UV method for the simultaneous quantification of triterpenic glycosides and aglycones in leaves of Centella asiatica (L.) Urb (Apiaceae). Journal of Chromatography B, 877: 2396-2402.
ShShukla. A, Rasik AM. 1999. In vitro and in vivo wound healing activity of asiaticoside isolated from Centella asiatica. J. Ethnopharmacol., 65: 1-11.

Veerendra KMH, Gupta YK. 2002. Effet of different extracts of Centella asiatica on cognition and markers of oxydative stress in rats. J. Ethnopharmacol., 79: 253-260.

Zhang FL, Wei YJ, Zhu J, Gong ZN. 2008. Simultaneous quantification of three major tritepenoid glycosides in Centella asiatica extracts by high performance liquid chromatography with evaporative light scattering detection. Biomed. Chromatogr., 22(2): 119-124. 